\title{
Sound Image of Indian Civilization
}

\author{
Tatyana Kartashova ${ }^{1, *}$
}

${ }^{1}$ Department of Theory Music and Composition, Faculty of History and Theory of Music, Saratov Sobinov State Conservatory, Saratov, Russia

*Corresponding author.Email: arun-rani@yandex.ru

\begin{abstract}
The Indian civilization created its own unique sound image, which significantly distinguishes it from other regions of the world. In Sanskrit treatises, the material world was considered as a sounding entity, had a sound nature. Sound was perceived as a specific self-sufficient phenomenon, as a matter that was able to harmonize all the elements of the universe. The sacral understanding of the sound leads to creating of a developed system that regulates time and conditions for the musical performance. For an Indian musician, sound is a complex multidimensional entity that embodies the whole meaning of being.
\end{abstract}

Keywords: India, sound, Indian music, Nada, Gandharva, Sangeet, raag

All music is part of the great God,

whose name is Sound.

(an Indian saying)

\section{INTRODUCTION}

The modern world is multicultural and multivoiced. Each region-civilization ${ }^{1}$ has its own sound image, thanks to which it can be identified. Generalizing matter is the sound, which performs numerous functions and acts as a cultural and genetic code. The sound-musical image of any civilization is a projection of a world model developed inside it, it reflects the essence of this civilization and weaves into the general canvas of the sounding universe.

The Indian civilization formed a specific system of sound understanding in ancient times, and it still holds its meaning. The entire culture of the region throughout its long continuous history looked upon the world through a "magic crystal" of sound, built its "relationship" to the Universe as a boundless ocean of tone. In India you can still hear that "all music is part of the great God whose name is Sound".

To describe the art of sound, the traditional Indian music theory offers two terms: gandharva is an ancient concept that crystallized in the process of developing of the ancient Indian epic. It can be translated as "heavenly, sublime" music. The other, newer term is sangeet.

The term was coined by the founder of the scientific research of musical cultures of the world, a Moscow researcher G.K. Michailov (1938-1995).
The gandharvas are celestial geniuses, mythical singers and musicians who played and sang to please the gods. Their tasks included to speak the divine truth (like the muses), which made them mediators between the humanity and the gods. Both muses and gandharvas are responsible for musical skill given to people: muses give musical and poetical talents, gandharvas instruct in playing instruments and singing. In this regard, both Ancient Greece and India understood music as a divine art. At least in India this idea remains.

The later term applied to musical performance today is sangeet. It comes from the words "san" (together) and "geet" (song). Therefore, the term can be translated as "a song and everything that goes with it" and implies a synthesis of arts united by their connection to the sound, music in all its variety, dance (gesture, movement) and dramatic performance, which are the three inextricably linked arts of artistic activity. According to Indian performers, the word "sangeet" can be also translated as "bringing together (this body, mind and spirit) and expression of everything", for every musician is on a search for the infinite, striving to comprehend, sense and convey it to the audience. Merging with the universe is an eternal ideal of the Indian spirit, the attitude to the variety of life's manifestations as to different facets of the infinite One is the norm of the understanding of reality in that country. The unity of the multitude of India is a reflection of its history, for many centuries associated with constant "infusions" of foreign cultural traditions, mixing of races and peoples, which did not change the 
unique face of the country, but served as an elixir of health and longevity to it. The readiness India accepted everything that joined easily with its own matter correlated with and possible resulted from the long developed sense of a different kind of unity - the unity of the life and the Universe.

The concept of "sangeet" focuses in itself the idea of all-encompassing sound of nada projected to the complex of arts which appeal to the general sound matter; it's comprehension of the unity of all the heterogeneous elements of the Universe on the basis of sound in its different manifestations. Based on the ancient religious and philosophical ideas, the sound itself contains the origin of the world. In Sanskrit treaties, the material world is considered to be a sounding entity, to have a sound nature and to come from nada where $n a$ is the universal breathing (prana $)^{2}$ and $d a$ is the life-giving fire. The ancient Indian philosophers meant the merging of this two elements to lay the foundation of the Universes. The scholar Mukund Lath in his famous work "A Study of Dattilam" writes: "In his treaty, Matangi explains in great detail the anatomical process of how the sound or nada is reproduced in a human body. In the center of the body is brahmagrandhi, the seat of the Brahman. Inside the brahmagrandhi there is a vital breath - prana which sets in motion the vital fire - vahni. The union of fire and breath results in nada, or the sound" [1].

\section{THE CONCEPT OF NADA}

The category of nada has also a mythological understanding. The wind and fire which nada originates from can be interpreted as the main Induist deities: "The sound appears from the joining of the vital air (prana) and the finest creative yearning known as the energy (agni). The symbols of air and fire are Shiva and Shakti for Shaivites and Vishnu and Lakshmi for Vaishnavites. The vital air and energy, as well as Shiva and Shakti or Narayana-Vishnu and Lakshmi are considered to be the first cause of our vast Universe. The sound evolves in the finest form and gradually materializing comes out as a musical sound through the human vocal cords. That is the most fascinating story of creating and making the musical sound of the world" [2]. In general, the nada concept covers "mystical, religious, cosmological, empirical, and scientifical" [3]

A curious fact is that, according to the ancient Indian physiologists, the life energy (prana) runs along the vertebra through the channel "susumna" like "a spider who runs and comes back to the centre of its web" [4]. And like the threads of the web, the hollow pipes of "nadi", the energy conduits run in all direction from the "susumna". In the Indian medicinal treaties the word "nadi" refers to tendons, veins, arteries, vessels, etc. In his commentary to "Sangeet Ratnakara", Kallinatha (ca. 1450) said when Sharngadeva explained emerging of "shruti" he meant by "nadi" the tantrian energy channels. The lowest audibility, in the commentators opinion, occurs because of the air passing through the hollow pipe of nadi "Pingama". levels of meaning, representing a phenomenon of the all-absorbing significance for the Indian culture.

The traditional Indian teachings say that the sound is a god - Nada Brahma. The Indian philosophers understood nada not as a sound itself, but as a potency of sound that is present in the space around us. The cosmogonic concept of the "world sound" was always associated with the highest absolute - the Brahman and personified in the image of various deities (for example, the goddess of arts Sarasvati, etc.).

According to the ancient Vedic teaching, there are two categories of sounds. The first is a vibration of the ether (akasha), the upper cleaner layer of the atmosphere, which is called anahata of nadas (this sound is inaudible, or better to say "unstruck", notmanifested); this sound of the Universe only the enlightened can hear" ${ }^{3}$."The sound unstruck is called the sound of akasha. The divine beings find their peace in this sound; it absorbs also the minds of the great yogis who train their spirit constantly. Thanks to this sound they both achieve the complete freedom", we read in "Sangeet Makarandha" (VIII), the work by the legendary Narada. The doctrine of akasha is supposed to be born in the ancient times to explain the nature of the sound. This term should be understood as a name of a specific sounding substance, invisible and intangible, filling the entire space. The sound of akasha cannot be heard by humans and is called "not-manifested" (unstruck) sound. The other category is the audible ("struck") sound, ahata of nada. There are musical and non-musical sounds produced by the nature and humans.

Thus, the essence of the nada concept boils down to the idea of sound as a specific vibration, the finest energy that materializes as a sound image, and human body is considered as a natural "sounding vessel". In this regard, the famous Indian Sufi Hazrat Inayat Khan (1882-1927) wrote: "All creation came from a vibration which is called Nada in India. < ... > Man loves music more than anything else, because music is his nature, it comes from vibrations, and he is a vibration himself" [5].

Pythagoras wrote in the sixth century BC about this music of the spheres. According to his teaching, the complete union of soul and body can be achieved only as a result of catharsis, the path to which lay through the knowledge of the musical and numerical nature of the Cosmos. The cleansed soul got the ability to remember its previous lives by entering into the perfect cosmic harmony. According to Pythagoras, this cosmic harmony can be presented in numbers as the "fourfold" - a sum of the first four numbers: $1+2+3+4=10$. In contains the basic musical intervals - octave, fourth and fifth that correlate to the sound of the sun, the moon and stars. But only the chosen and devoted disciples could achieve this catharsis. 


\section{THE PHILOSOPHY OF SOUND AND ETHICAL AND COSMOGONICAL CONCEPT IN INDIAN CLASSICAL MUSIC}

On the South Asian subcontinent, the concept of sound was formed in the II-I millennia B.C., based on giving it the meaning of the first cause of the Universe and the cause of all things, which received religious and philosophical meaning in the sacred texts and tradition of treaties. So, in "Brihaddeshi" (V-VII century) by Matanga we read that the sound is the highest bosom and the cause of everything. Sound is an attribute of the eternity, the perfect peace. The Tamilian poet Iraiyanar (IV century) in his "Musical Grammar" supposes that the sound builds the entire space of the Universe: it is finer than the ether (akasha) and any matter. The words and lines from the Vedas and all other sacred texts would be dry without this vital moisture, Iraiyanar says.

Sound was perceived not as an element for building a musical composition, but as a special self-sufficient phenomenon, acting as a matter that not only served as the source of the material world, but was also able to harmonize all the elements of the universe. This attitude to sound matter can be seen already in the Vedas ${ }^{4}$. Starting with the "Rigveda", or "Veda of hymns", a canonized system of rules for reciting the text was introduced, correlating sound in height, volume, length, and expression. The Vedic texts were always considered sacred, only the highest caste of Brahmans was allowed to know them. Therefore, the tradition was handed down in a process of long and meticulous training requiring many years, when the entire set of rules and the finest details of utterance were passed down orally. This act of representation of sound matter has a deep sacred meaning: With the help of sound, one can join the essence of the universe, its highest harmony and spirituality.

It is the sacred ideas about sound and its influence on space and people that led to the development of a detailed system that regulates time and conditions for the performance of musical compositions. This refers to the theory of time correlation of raga music, which assumes that the time of day is directly related to the

The Vedas (Sanskrit "knowledge", "teaching", "wisdom") are monuments of the ancient Indian literature that can be compared to the biblical text or the Ancient Greek epic by Homer. They are considered one of the oldest Sanskrit sacred texts of Hinduism in the world. The Vedas are believed to originate in the era of the invasion of Hindustan by the Indo-European Aryan tribes (about 1500 BC). According to the modern Indological science, the Vedas were compiled during a period that lasted about a thousand years. It began with the "Rigveda" (the final design is usually attributed to the $\mathrm{X}$ century BC, the beginning to ca. 1700 BC). There are four Samheetas (collections of sacred texts of Hinduism) with mantras, repeated as prayers, which are used in various religious rituals and addressed to the gods: Rigveda ("Veda of hymns"), Yajurveda ("Veda of sacrificial formulas and interpretations"), Samaveda ("Veda of chants"), Atharvaveda ("Veda of magic spells"). presentation of a particular sound $(\mathrm{raga})^{5}$ or a metrorhythmic (Tala) ${ }^{6}$ scale. As known, every raga should be presented not only at a certain time of the years (season, periods of rains or extreme heat), but also at a specific time of day (night, morning, dusk): Vassant means spring, Hindola means swing, and Megha - a cloud. That's the only way to achieve the perfect calmness that leads to inner satisfaction (harmony in the soul and in relationship to the Universe) and enjoying the experienced sound, which of the main goal of any art. Non-compliance with these laws, according to the concept of ancient Indian philosophers, can lead to bodily diseases and even destroy the human body.

For an Indian musician, sound is a complex multidimensional entity that embodies the whole meaning of life: from the harmony of the world to the personal spiritual intentions of an individual. While playing music, a musician models the vibrations of the universe, resonates with it, and reaches the highest aesthetic pleasure, or Rasa. It is the understanding of music that brings the consciousness of the individual to the apprehension of the true meaning of the world and makes it possible to feel its eternal and unchangeable essence. Hence the specific worldview of a musician, who is aware to be chosen among the gods and humans, because only he is able to reach a more extensive "field" of the eternally and boundlessly sounding Cosmos. Which means, he is closer to understanding the Truth ${ }^{7}$. At the same time, he also has a huge responsibility to the world, since it is in his power to influence the life of the Universe with the help of sound, to strengthen or destroy its harmony. As the greatest Master Ravi Shankar said in an interview, music for us is "a spiritual discipline that must be learned on the way to self-improvement" ${ }^{8}$. It is not a coincidence that the long and laborious training in Indian classical music begins with the study of the $\operatorname{svaras}^{9}$ (tones), with gaining skills of managing energy,

Raga "as a Sanskrit word "raag" is masculine, but in Russia there is a tradition to use "raga" it as feminine. Its etymology is related to the root "ranj", from the verb "to colour", "to give a shade". Raga is a multi-level concept: 1) in the theory of Indian classical music it is a system of techniques to develop the sound matter, after the impact of which humans enter a certain emotional state (Rasa);2) a scale with the endogenous hierarchy of tones, and the strict system of their relationships; 3) a model-frame of a musical composition" [6].

6 "Tala (from Sanskrit "clap hands") is 1. a metrorythmical system in the Indian music; 2. a cyclical arrangement of musical time units" [7]

The Indians thought that a musician can create a kind of micro universe around himself

8 From a personal conversation with the Maestro in 2005 in Kamani auditorium (New Delhi).

9 Svara is "a tone zone where the sound can get higher and lower in a microchromatical way. The main scale of the North Indian musical system contains 7 svaras, abbreviated as: $\mathrm{Sa}$ (shadja), $\mathrm{Re}$ (rishabha), Ga (Gandhara), Ma (madhyama), Pa (panchama), Dha 
developing ear and performing skill to the level when the sound becomes weightless, floating, melting and can even get direction and "rotation".

For an expert of Indian music the first few sounds are sometimes enough to understand what he is going to hear. Sometimes this premonition comes already at the sage of tuning the tampura ${ }^{10}$ - a constant member of an accompanying ensemble. The sound of a tampura carries several meanings that seem to follow one another at the same time. The direct observation of the process of music making makes you think about it in the first place. The significance that Indian musicians attach to this instrument, which is not a solo or melodic one at all, confirms the assumption that for an Indian, the sound of the tampura not only serves as a reference point and a "psychological axis", but is a manifested (though microscopic) part of the eternal and allencompassing, generating and absorbing Cosmic Absolute - Brahma. Interesting is an observation of the famous Indian researcher Raghava Menon: "...The

(dhaivata), Ni (nishada). Each of the tones included in this scale can only approximately correspond to the European concept of scale tones, since the Indian music does not have an even temperament, and for it the most subtle gradations of the sound level become paramount. If you fix the wave zonal frequency of European notes (c, $\mathrm{d}, \mathrm{e} . .$.$) and Indian swaras ( \mathrm{Sa}, \mathrm{Re}, \mathrm{Ga} \ldots$ ), the charts will not match. Therefore, it is impossible to identify the diatonic major scale with the highly organized pitch system of Indian music. Starting from a certain altitude in the sound space, the swara "continues" almost to the "beginning" of the next one, as if "clinging" to it and smoothly flowing into it. It is related to the concept of "Shruti". Swara is a masculine noun in Sanskrit, and Shruti is a feminine noun. In a musical context, this can be symbolically interpreted as Nara-Nari (male-female), similar to the Chinese "Yan-Yin", a manifestation of the male and female principles. Within the sound space from the lower Sa to the upper Sa, defined as saptaak ("octave" as an interval), there are 22 Shruti (literally "what is heard, what is discernible by ear"). Shruti can be interpreted as a minimum interval that lowers and raises the sound; it does not have an absolute acoustic value. The interval between tones is determined by the number of shruti in it: Sa$\mathrm{Re}-4, \mathrm{Re}-\mathrm{Ga}$ - 3, Ga-Ma - 2, Ma-Pa - 4, Pa-Dha - 4, Dha-Ni - 3, $\mathrm{Ni}-\mathrm{Sa}-2$. All shrutis have their own names and are divided into 5 main classes according to their aesthetic purpose: burning, neutral, tender, pitiful and broad. In various ways, the shrutis are combined and distributed among the swaras: the largest number of shrutis - four - is included in the "zone" of the swaras Sa, Ma and Pa (I, IV and V tones), three shrutis are contained by Re and Dha (II and VI tones), two - by Ga (III) and Ni (VII). The grouping of the Shruti into the zone "field" of the swara occurs according to the degree of the functional significance of each swara. In ancient treatises, the swaras, which included 4 shrutis, were considered "large" and two of them were associated with the main deities of Hinduism (Sa - with Brahma, Ma - with Shiva) and one - $\mathrm{Pa}$ - with the divine sage Narada. Besides, they belong to the highest caste in Ancient India Brahmans (priests). Svaras that had three shrutis, the "middle ones", belonged to the caste of Kshatriya (warrioirs) and very associated with "secondary" deities: Re with Tumburu, Dha with Ganesha. The status of Maishyas (artisans, merchants), and in some treatises even the lowest caste, the Sudras, belonged to the "lesser" swaras (Ga and $\mathrm{Ni}$ ) that had two srutis. Thus, the differentiation of svaras was aligned with the established trinity: big - medium - small" [9].

10 Tampura is a bourdoning four-string instrument that produces the effect of "buzzing" and "humming". constant tone of the tampura gives rise to numerous sounds of the composition, which live, develop, split, but constantly strive to return to the bosom of the musical infinity that gave birth to it and, in the end, merge with it" [8].

In our view, this is a very important point. Sound is represented here as a kind of "nuclear charge" of the entire composition, as a complete set of tones in it pressed in time, including imaginary, illusory sounds. Let us add, however, that not only this information is encoded in sound, but also the entire accumulated intonation experience of culture, the modal structure of thinking, certain types of sound unfolding and so on. In the European music, sound is the smallest element of the musical structure, the "cell", and the focus of perception shifts to its compositional, acoustic and aesthetic qualities. In the understanding of the Indian civilization, each sound acquires its own special meaning, carries of a certain informational content and causes specific sensations. According to the metaphoric definition of G. Mikhailov, a single sound in such "loquacious" cultures (i.e. committed to wide-range, rich melodic lines), resembles "a chip on a rare gem skilfully groped by a master and exposed in one blow, revealing infinitely readable patterns and their combinations in the complex structure of the stone"11. Singer who lay their voices over the stable rhythmical sound of the tampura strive not to dominate in the sounding mass, but to weave their voices as an intricate pattern in the lace which fills all surrounding space.

In special schools in India very lesson in the classical vocal music starts with working on the sound Sa ("shadja") ${ }^{12}$ which is the very beginning, the fixed centre. It is a symbolic sound, an immersion in peace. It means not only the bringing a singer's voice box into the working condition, but penetration into the sounding essence, reaching to the balance inside as the traditional Indian philosophy says. Gurus ${ }^{13}$ often forbid their pupils to sing or play any other sound until they "find" and master their true $S a$ According to the musicians themselves, all the Indian music rests in the womb of $S a$. The sound has no form, "boundaries, it is in a state of ever "coming and going"" [10]; it is the power that creates a harmonious world and its beginning. The Indians think, the final hit in a note to finish a composition focuses "a sacred creation of the Cosmos anew - complete and round. It contains the sound of cosmic infinity, a sense of harmony" [11]. Dr. Kapila Vatsyayan states: "Sound creates a harmonious

11 There are excerpts from lectures by G. K. Mikhailov, recorded by the author of the article in 1986 at the Moscow State Conservatory.

12 The term "shadja" means literally "born to the six". Shadja may be set at any pitch (convenient for the voice or the instrument) that remains the same during the whole composition.

13 Guru is a spiritual mentor, teacher in the Indian tradition. 
structure that has its own architectonics. Then the cosmos grows in concentric circles, perhaps with the help of one or three octaves, followed by a thorough study of the world in all its diversity of micro-sounds, light, shadow, and accents. The design of sound structures reflects the infinite variety of life, the main goal is achieved: the stationary center in combination with a Lotus-like frame causes a sublime aesthetic sensation..." [12].

It is interesting to note that the Indian treatises mention five types of sound manifested through various parts of the human body: elusive, subtle, clear, obscure, and artificial. In the "Sangeet Makarandha" treatise this is said in this way: "A soul that seeks to express itself in the speech, excites the mind; the mind excites the bodily fire, and it moves the air inside the note of Brahma. Moving gradually upward, it generates sound in the navel, heart, throat, head, and mouth. According to the five places of sound formation, five types of sound are distinguished" [13]. The peculiar "physiologism" of this concept was in line with the theories of natural philosophy developed by the ancient Indian schools - a tendency that reflected already in those distant times in a specifically Indian form the desire to identify and express the relationship between processes occurring in the Cosmos, Nature, and Man and sound. In this respect, the Indian culture was already extremely wise and far-sighted in ancient times.

\section{VOCAL AND INSTRUMENTAL MUSIC OF SOUTH ASIA}

The human body, according to the ancient Indian philosophical doctrines, is the divine "model" of the ever-sounding Cosmos, the most important source and conductor of sound. That is why in India the priority belongs to vocal music, which is still considered an art of a higher order than instrumental music, which is more indirectly related to the process of producing sound matter. Faith in magical power of the chanted word gave rise to many legends of old times. They tell about miraculous influence of the sound on the nature and humans and are still relevant to the modern Indian society.

The very philosophy of sound in India considers each individual tone as a complex, multi-component entity, embodying a rich palette of meanings and touching upon the sphere of subtle sensations, experiences, and intuition. And in this sense, Indian music is not homophonic, as it may seem at first glance, but super-polyphonic, but this polyphony is a kind of world of subtle matters and energies available to the developed ear, soul and intellect. In accordance with this approach, most South Asian instruments involve extracting a tone wrapped in a glittering shell of explicit and implicit glide sounds, accompanied by an ephemeral overtone plume. This purpose is served by bourdoning strings (chikari) used for many strings instruments and different tricks in the layout of resonators, special performing techniques.

Revealing only an indirect connection with the word, instrumental music occupied for a long time a subordinate place in the hierarchy of arts in relation to vocal music. Even in the XX century, despite the existence of a fairly developed self-sufficient instrumental traditions, even brilliant virtuososinstrumentalists were considered second-class musicians next to fairly average vocalists. Only a powerful surge of interest in Indian music from the West significantly corrected this ratio, because it was instrumental music that quickly found its way to the hearts of foreign listeners: there was no problem of misunderstanding the verbal text and, most importantly, the aesthetics of sound production itself, refracted in the familiar timbres of the string and other sound sources, was not so shocking. In the 1960s, the wide spread of popular music and jazz played a huge role as a kind of "testing area" for the development of mass interest to the musical art of India. The introduction of Indian music to thousands of the young led to a real sitar "explosion". In that time sitar ${ }^{14}$ gained international fame due to the world tours and the brilliant performance of the unequalled performer Ravi Shankar. Many popular musicians, starting with the idols of that time, "Beatles", "Rolling Stones", "Traffic", "Mahavishnu Orchestra" and others who used elements of sitar's expressivity in their compositions became the followers of famous gurus, went to India to fully immerse in the atmosphere of the world that beckoned them.

And even today, it is impossible not to be surprised at how large and diverse the world of instrumental music is, represented by thousands of interesting traditions. A musical instrument as a cultural phenomenon in the Indian civilization has made it through the evolutionary path not less complex than the singing human voice. The technique of sound production and creating sound canvas with such instruments as veena ${ }^{15}$, sitar, sarod ${ }^{16}$, sarangi ${ }^{17}$, bansuri (flute) etc. was being refined for centuries. Next to the musicians-performers, crafters worked tirelessly on improving design of instruments, trying to

14 The sitar is a stringed instrument with a long neck: it has five metal, two chikari (burdoning) and seventeen additional (resonating) strings.

15 Veena is an Indian cither, in ancient times called kinara. It is an instrument of the goddess Saraswati, the patron of arts. A veena consists of two pumpkin resonators, a hollow bamboo or wooden pipe attached to them as a neck, 4 metallic strings and some additional strings for bourdoning and virtuoso passages (jhala).

16 The sarod is an instrument from the lute family. It has seven strings and two chikaris (bourdoning); is played with a plectrum

17 The sarangi is a bow instrument with three or four strings 
give their wooden, metal, pumpkin, clay, bamboo bodies such properties that would provide amazing depth and transparency, strength and tenderness of sound, which would make unlimited possibilities for the musician to catch in the immeasurable "ocean of sound" its finest and most diverse waves.

The development of the instrumental tradition as an independent field of classical Indian music is also connected with other instruments. Each of them emancipated from the "custody" of vocal music due to brilliant musicians who improved their instruments and techniques of playing them, created their own pool of expressive means and examplary texts for a particular instrument. Their names are known not only in India, but also outside the country.

\section{CONCLUSION}

So, the Indian civilization has created its own unique sound image, which significantly distinguishes it from other regions of the world and is woven into the overall picture of the Pax Sonoris, or Sounding world, uniting the great triad Sound - Man - Universe.

And in conclusion, I would like to quote the words of the famous Canadian scholar and composer Murray Schafer who made an urgent appeal to all the inhabitants of the planet to "learn the sound tuning of their world", and support his idea that the unity of Man and the universe is always based on Harmony.

\section{References}

[1] M. Lath, "A study of Dattilam: a treatise on the sacred music of ancient India". New Delhi, Impex India, 1978, p. 198.

[2] S. Prajnanananda, "Music of the nations", New Delhi, Munshiram Manoharlal publishers Pvt. Ltd, 1973, p. 44.

[3] R. Sanyal, "Philosophy of Music", Bombay/New Delhi, Somaiya publications PVT. LTD, 1987, p. 77.

[4] Sangitaratnakara of Sarngadeva: Text and English Translation Chapter 1 / Ed. by Stringy R., Prem Lata Sharma. Vol. 1, New Delhi, Munshirm Manoharlal, 1991, pp. 148-151.

[5] H. Inayat. Khan, "The Mysticism of Sound and Music", Boston, Shambala, 1991, p. 185.

[6] T. V. Kartashova, "Up-shastriya as a common sound space of musical culture of North and South India", Moscow, Composer, 2010 , p. 538

[7] Op. cit., p. 542.

[8] R. B. Menon, "The magic of the raga", Mumbai, Somaniya publ., 1998, p. 67

[9] T. V. Kartashova, "Up-shastriya as a common sound space of musical culture of North and South India", Moscow, Composer, 2010, p. 541.

[10] R. B. Menon, "The magic of the raga", Mumbai, Somaniya publ., 1998, p. 86.

[11] K. Vatsyayan, "Ideological basis of cultural heritage", New Delhi, Sangeet Natak Akademi, 1984, p. 14.

[12] Op. cit., p. 17.
[13] R. Sanyal, "Philosophy of Music", Bombay/New Delhi, Somaiya publications PVT. LTD, 1987, p. 17. 